\title{
A Literacia Digital Frente ao Discurso Anticiência e às Fake News
}

\section{Digital Literacy Against Anti-Science Speech and Fake News}

\section{Alfabetización Digital Contra el Discurso Anticiencia y las Fake News}

\author{
iD (9) Doglas Cesar Lucas \\ Universidade Regional do Noroeste do Estado do Rio Grande do Sul (UNIJUÍ), ljuí, Rio \\ Grande do Sul, Brasil \\ doglasl@unijui.edu.br \\ Lucas Oliveira Vianna \\ Universidade Regional do Noroeste do Estado do Rio Grande do Sul (UNIJUÍ), ljuí, Rio \\ Grande do Sul, Brasil \\ lucasoliveiravianna@gmail.com \\ Matheus Thiago Carvalho Mendonça \\ Universidad Nacional de La Plata (UNLP), Buenos Aires, Buenos Aires, Argentina \\ thiago.matheus72010@gmail.com
}

Resumo: A era da pós-verdade caracteriza-se por uma conjuntura sociocultural em que fatos objetivos têm menos influência em moldar a opinião pública do que apelos a crenças do indivíduo. Essa crise epistemológica é um cenário fértil para a propagação de notícias falsas, o que afetou também a comunidade científica, que tem sofrido com a expansão de discursos pseudocientíficos e anti-científicos nas redes sociais, com o escopo de minar a credibilidade pública de instituições envolvidas na produção de conhecimento. Tal postura 
foi adotada, inclusive, por políticos e membros do governo brasileiro, que disseminaram conteúdo falso para justificar determinadas medidas políticas. $\mathrm{O}$ trabalho aborda o problema a partir do método indutivo, por meio da pesquisa de revisão bibliográfica. Propõe-se a literacia digital como meio de combate às fake news, efetivação da cidadania e, especificamente, permeabilização da comunidade externa ao conhecimento produzido no meio científico.

Palavras-chave: Fake News. Pós-Verdade. Anti-ciência. Literacia Digital.

Abstract: The post-truth era is characterized by a socio-cultural context in which objective facts have less influence in shaping public opinion than appeals to the individual's beliefs. This epistemological crisis is a fertile scenario for the spread of false news, which also affected the scientific community, which has suffered from the expansion of pseudoscientific and anti-scientific discourses on social networks, with the aim of undermining the public credibility of institutions involved in the production of knowledge. This attitude was even adopted by politicians and members of the Brazilian government, who disseminated false content to justify certain political measures. The work approaches the problem from the inductive method, through bibliographic review research. Digital literacy is proposed as a means of combating fake news, effective citizenship and, specifically, permeability of the external community to the knowledge produced in the scientific community.

Key Words: Fake news. Post-truth. Anti-Science. Digital literacy.

Resumen: La era de la posverdad se caracteriza por un contexto sociocultural en el que los hechos objetivos tienen menos influencia en 
la formación de la opinión pública que las apelaciones a las creencias del individuo. Esta crisis epistemológica es un escenario fértil para la difusión de noticias falsas, que también ha afectado a la comunidad científica, que ha sufrido la expansión de discursos pseudocientíficos y anticientíficos en las redes sociales, con el objetivo de minar la credibilidad pública de las instituciones involucradas en la producción de conocimiento. Esta actitud fue adoptada incluso por políticos y miembros del gobierno brasileño, quienes difundieron contenidos falsos para justificar ciertas medidas políticas. El trabajo aborda el problema desde el método inductivo, a través de la investigación de revisión bibliográfica. Se propone la alfabetización digital como un medio para combatir las fake news, la ciudadanía efectiva y, en concreto, la permeabilidad de la comunidad externa al conocimiento producido en la comunidad científica.

3

Palabras-clave: Fake news. Posverdard. Anticiencia. Alfabetización digital.

Data de submissão: 30/09/2020

Data de aprovação: 10/12/2020 


\section{Introdução}

“Cada público tem seu próprio universo de discurso e [...] humanamente falando, um fato é apenas um fato em algum universo de discurso" (PARK, 1940, p. 679). Três quartos de século antes de os dicionários de Oxford nomearem a palavra "pós-verdade" como a palavra de 2016, Robert Park - um ex-jornalista e um dos fundadores da Escola de Sociologia de Chicago - entendeu que notícias falsas são um elemento intrínseco de qualquer ecologia da informação. “O jogo é velho como a humanidade. É de engano e de mentira que se trata. A novidade está, como em tudo o mais nos dias que correm, no que os computadores e a rede mundial permitem fazer com isso" (MESQUITA, 2018, p. 33).

Muito antes de Mark Zuckerberg começar a ser tratado como um empresário ganancioso, editores notáveis como William Randolph Hearst e Charles Foster Kane exploravam o potencial comercial das notícias falsas, assim como outros que os precederam e os sucederam. Além dos esforços deliberados para distorcer ou desinformar, os erros não intencionais detectados pelo público e a suspeita de que possa haver outros não identificados - têm reforçado uma postura cética das pessoas sobre a suposta veracidade das notícias. No entanto, não é exagero dizer que a principal inquietação das ciências sociais, após a ocorrência de disputas políticas afetadas pela disseminação de notícias falsas, tem sido uma sensação coletiva de choque, indignação e desespero com o aumento da sua prevalência.

A maior parte das incursões científicas sobre notícias falsas tem se concentrado em questões de produção, como a localização e as possíveis motivações de vários fornecedores de desinformação, a mudança no cenário geopolítico da guerra de informação, 
os benefícios econômicos para a mídia. mecanismos de comunicação e busca e a necessidade e comodidade de implementação de restrições técnicas e/ou financeiras que possam minimizar a divulgação de notícias falsas, entre outras. O foco nas questões de produção é importante e todas essas são instâncias válidas cuja discussão é pertinente. No entanto, o presente artigo, embora verse sobre alguns dos pontos anteriores, pretende tratar acerca de algumas dinâmicas de recepção crítica que poderiam estar subjacentes à maior presença de notícias falsas no ambiente contemporâneo do que no passado.

Para tanto, sobressai-se como especialmente relevante uma abordagem interseccional entre Sociologia e Direito, a fim de compreender não apenas como lidar com o problema, mas também como interpretar seu advento a partir dos contextos histórico, sociológico e cultural que the serviram de nascedouro, quais sejam, a Pós-Modernidade e a pós-verdade. Para realizar tal proposta, o presente artigo valeu-se do método indutivo, por meio da revisão bibliográfica.

Por fim, procede-se a uma análise do fenômeno das fake news como veículo propagador do discurso anti-ciência - em alta no cenário da pandemia de COVID-19 -, a partir tanto das estruturas teóricas previamente assentadas quanto dos dados empíricos que têm sido angariados pelas Ciências Humanas e Sociais.

\section{As Fake News como Semente e Fruto da Pós-Verdade}

Para uma adequada compreensão do problema das fake news, é essencial que se proceda à contextualização do fenômeno no panorama sociocultural em que inserido, para o que se mostram úteis categorias sociológicas como pós-modernidade e pós-verdade. 
A Universidade de Oxford, ao eleger, em 2016, o termo "pós-verdade" como a palavra do ano, definiu a expressão como "um substantivo que se relaciona ou denota circunstâncias nas quais fatos objetivos têm menos influência em moldar a opinião pública do que apelos à emoção e a crenças pessoais" (OXFORD, 2016). Trata-se, pois, de uma conjuntura cultural caracterizada por uma opinião pública afetada pelo pathos público, em que “importa menos a pretensão de validade do que a expectativa de realização de desejo que a informação venha a satisfazer" (GIACOIA JUNIOR, 2017), propiciando o surgimento de um espaço público "onde se tende a praticar e difundir o uso de argumentos [...] mais ligados à dimensão emocional do que à dimensão racional e fundamentada", para os quais "as provas de refutação são geralmente ignoradas ou desvalorizadas" (CARDOSO et al., 2018, p. 15).

Nesse norte, Mclntyre (2018) elucida que o prefixo "pós" do neologismo em questão refere-se não à ideia do "depois" da verdade, em um sentido temporal (como em 'pós-guerra'), mas no sentido de que a verdade foi superada, que ela é irrelevante. A pós-verdade seria, em suma, a noção de que crenças ou impressões são constitutivas da realidade (CUNHA FILHO, 2019), estimulando os indivíduos a distorcer os fatos para encaixá-los em suas opiniões, em vez do contrário (MCINTYRE, 2019). Não surpreende, portanto, que a sua eclosão ocorra no contexto sociocultural da pós-modernidade.

O pós-modernismo oferece suporte filosófico à pós-verdade na medida em que proclama que todos os fatos sociais são socialmente construídos e que argumentos sobre um certo fato político ou social estão invariavelmente associados a uma narrativa específica (CUNHA FILHO, 2019). A ênfase emotivista e identitária do pensamento pós-moderno também demonstra fertilidade para o 
surgimento de notícias falsas, uma vez que, nesse ambiente sociocultural, "as escolhas [...] dão-se muito mais baseadas em razões sensíveis e na emoção do que em raciocínios lógicos e informações exatas" (GENESINI, 2018, p. 48).

Lara Mesquita diagnostica o seguinte:

No estágio pré-tecnológico, quase artesanal, aquilo que viria a se transformar na "pós-verdade" evoluiu do "patrulhamento ideológico" de antes do poder para a repressão e a agressão armadas da disputa por uma hegemonia geoestratégica, até desaguar, depois de detida no seu avanço militar, na tentativa de impor uma "hegemonia cultural" em busca do "consentimento social" para um conjunto de convicções, normas morais e regras de conduta semeadas com um trabalho meticuloso de "superação" induzida de crenças e sentimentos estabelecidos, conducente à autoimolação das democracias, a ser obtida pelo "controle dos meios de difusão cultural da burguesia", e à "cooptação de artistas, professores e intelectuais orgânicos" a serviço da conquista do poder político (MESQUITA, 2018, p. 35-36)

Nesse sentido, as notícias falsas prosperam a partir da pós-verdade, ao passo que também compõem uma ferramenta de sua construção, constituindo, assim, um verdadeiro ciclo vicioso.

Não se pode olvidar, ainda, a inter-relação do surgimento das fake news com o advento do ambiente digital em si, que, por questões diversas - algumas relacionadas à própria natureza do meio - possui critérios distintos de validação em relação às mídias clássicas jornalísticas (MCDOUGALL et al., 2018). Ao passo que nos meios tradicionais físicos o lucro era oriundo das assinaturas dos 
leitores, as plataformas de notícias no meio digital, por serem gratuitas, obtêm suas receitas pelos anúncios visualizados em suas respectivas páginas, o que "introduz na questão das fake news um factor motivacional que contribui para a sua existência: a dimensão económica das instituições jornalísticas ou outras, nomeadamente inscrita num modelo comercializável na internet baseado em anúncios" (CARDOSO et al., 2018, p. 19).

Desse modo, portais midiáticos com uma história de confiabilidade e ética jornalística estão sendo substituídos por alternativas digitais que concorrem avidamente entre si por usuários (MCDOUGALL et al., 2018). Tal mecanismo dá azo a que as empresas utilizem do denominado "clickbait", artifício segundo o qual os portais, "usando-se de uma relação direta entre número de visualizações e receitas", produzem "títulos e/ou conteúdos que, de forma deliberada, servem para ser clicados pelos utilizadores", reforçando a estreita correlação "entre fake news e o aspecto emocional chamado em causa pela noção de pós-verdade" (CARDOSO et al., 2018, p. 19).

Nesse novo ambiente, o sucesso de um portal depende não tanto da confiabilidade histórica do seu conteúdo ou da ética jornalística, e sim da sua facilidade de localização nas mídias e do uso de mensagens personalizadas para captar a atenção do público-alvo (HOBBS, 2017). Esse sistema contribui para a disseminação de notícias falsas, visto que essas têm mais probabilidade de serem compartilhadas através da mídia e viajam mais rápido do que o conteúdo verdadeiro (VOSOUGHI; ROY; ARAL, 2018). Isso deve-se, em grande parte, à capacidade das fake news de dialogar com o pathos do leitor - para instrumentalizar um vocábulo aristotélico e nesse evocar profunda simpatia e emoções intensas, tais como ansiedade ou raiva, as quais ensejam mais compartilhamentos do que conteúdos neutros (MCDOUGALL et al., 2018). Por essa razão, 
há uma "tendência dos utilizadores partilharem muito mais as notícias caracterizadas por uma linguagem e conteúdos sensacionalistas e excitantes" (CARDOSO et al., 2018, p. 19).

Em verdade, as fake news, em seu sentido mais amplo, podem existir "teoricamente desde o primeiro processo político da humanidade", mas é "com o surgimento dos meios de comunicação em massa, que se se criaram condições para que este fenómeno se tornasse uma dimensão fundamental da vida social e política" (CARDOSO et al., 2018, p. 19). Assim sendo, "a novidade não está nas fake news em si, mas na aparição de um instrumento capaz de reproduzi-las e disseminá-las com amplitude e velocidade inauditas" (FRIAS FILHO, 2018). Logo, embora o fenômeno não seja inusitado, é a atual dimensão por ele assumida que demanda novas abordagens.

Por fim, o impacto sociológico das fake news nos espaços públicos também está diretamente relacionado aos algoritmos utilizados pelas redes sociais, os quais filtram os conteúdos que serão expostos à pessoa, a partir das visões políticas e sociais mantidas pelo usuário, criando as denominadas "câmaras de eco ideológicas" (ROSENZWEIG, 2017; SUNSTEIN, 2001). Considerando que cada integrante da bolha é exposto seletivamente às opiniões com que concorda, desenvolve-se um fenômeno social intitulado "efeito do falso consenso", que traduz uma tendência de superestimar o quão comum a própria opinião é (MCDOUGALL et al., 2018). Essas comunidades "se tornam cada vez mais segregadas em termos de política, cultura, geografia e estilo de vida" (KAKUTANI, 2018, p. 105), contribuindo para a constituição de uma sociedade polarizada e fragmentada (FISHER; TAUB, 2018; LEVITSKY; ZIBLATT, 2018). 


\section{Fake News como Veículo do Discurso Anti-Ciência}

Nesse novo cenário, ganhou especial destaque a expansão de discursos anticientíficos observada no séc. XXI em vista de sua nocividade para o tecido social, o que tem causado alarme na comunidade mundial (KENRICK et al., 2018). A disseminação de fake news travestidas de conhecimento científico é especialmente perniciosa pois, além dos efeitos óbvios da ludibriação, a exposição continuidade a tal conteúdo pode levar as pessoas a deixarem de forma total de acreditar em fatos e duvidarem do próprio valor da ciência e das evidências científicas (VAN DER LINDEN et al., 2017).

A emergência desse fenômeno relaciona-se não apenas com a dificuldade em se efetivar uma permeabilidade entre as comunidades de produção do conhecimento científico e o público em geral, mas também com uma mudança ocorrida no próprio paradigma de comunicação, com o surgimento de foros de informação disputados por diversos atores, exatamente em um momento em que se vivencia uma crise epistemológica que mina a credibilidade pública de instituições envolvidas na produção de conhecimento (ALBUQUERQUE; QUINAN, 2020).

No campo da produção de conhecimento científico falso, destacou-se como especialmente nocivo em suas consequências um artigo fraudulento publicado no Lancet alegando que vacinas para sarampo, rubéola e parotidite epidémica seriam causadoras de autismo (WAKEFIELD et al., 1998), publicação que embasa teorias conspiratórias antivacina até os dias atuais. Há diversos temas "que ecoam nas redes sociais digitais em que pressupostos científicos universais são desacreditados e deslegitimados", tais como aquecimento global, terraplanismo e vacinação (OLIVEIRA, 2020, p. 22). 
Os efeitos deletérios das notícias falsas alcançam mesmo os processos democráticos, como foi observado no âmbito brasileiro desde a onda de protestos de 2013 que culminou com o impeachment da Presidenta Dilma Rousseff (BITTENCOURT, 2020). Posteriormente, o atual Presidente da República, Jair Messias Bolsonaro, em sua campanha eleitoral, valeu-se reiteradamente de notícias falsas para desprestigiar seus oponentes (BARRAGÁN, 2018; VISCARDI, 2020), com a associação contumaz de seu principal rival, Fernando Haddad, à pedofilia (CESARINO). Em suma, a principal estratégia eleitoral do candidato foi "colocar em suspeição as informações dos grandes meios de comunicação e dar crédito às informações vindas das redes fechadas e ancoradas em relações de confiança e proximidade" (ALMEIDA, 2019), artifício que foi reprisado por Bolsonaro durante a pandemia de COVID-19, com suas insistentes recomendações em favor de tratamentos médicos não amparados pela comunidade científica (LEMOS, 2020).

Além das "tradicionais" notícias sugerindo métodos preventivos ou tratamentos sem comprovação de eficácia, foi engendrada uma campanha sistemática por parte do governo no sentido de desacreditar as informações divulgadas pelas mídias e pela comunidade internacional como sendo parte de uma conspiração política, minimizando os riscos da doença e incentivando a população a menosprezar a necessidade de distanciamento social (CAPONI, 2020). Observou-se, ainda, o compartilhamento de diversas notícias falsas por parte do Presidente, seus Ministros, e Deputados Federais apoiadores, culminando inclusive na remoção, por mais de uma ocasião, de publicações dos políticos do Facebook e Twitter por violação dos termos de uso das plataformas (MARQUES, 2020).

Além do compartilhamento pessoal de notícias falsas, por diversas vezes o Presidente adotou uma postura provocativa, proa- 
tivamente buscando oportunidades de abraçar e ter contato sem máscara com seus apoiadores (RICARD; MEDEIROS, 2020). Destacou-se episódio em que o político, em recomendação de isolamento social após diversos membros de sua comitiva terem sido infectados com o vírus, descumpriu as orientações e apertou a mão de simpatizantes (MAZUI, 2020). Bolsonaro chegou a recomendar que seus apoiadores invadissem hospitais para obter provas de que o impacto da pandemia na Saúde Pública estaria sendo fraudulentamente superdimensionado e os hospitais estariam vazios (URIBE, 2020).

Observou-se, ainda, que a propagação dos discursos de Bolsonaro recebeu suporte frequente de perfis falsos automatizados ("perfis-robôs"). Exemplificativamente, um levantamento apurou que mais de $50 \%$ dos tweets que utilizaram a hashtag \#bolsonaroday - que foi a mais compartilhada na plataforma no dia 15 de março de 2020 - foram postados por perfis dessa espécie (KALIL; SANTINI, 2020). Os autores ressaltam que isso é relevante porque "ainda que os robôs não possam votar ou transmitir doenças, sua atuação nas redes sociais (ao se confundirem com usuários comuns), pode orientar o comportamento dos humanos e alterar de maneira significativa a tomada de decisão ou o comportamento" (KALIL; SANTINI, 2020).

É importante salientar que, conquanto tenha havido o emprego de diversas medidas de caráter restritivo/coercitivo, tais como retirada de publicações do ar e elaboração de mecanismos de fact-cheking, as fake news relativas à pandemia lograram êxito em alcançar a comunidade externa e permanecem sendo acreditadas por grande parte dela (RICARD; MEDEIROS, 2020).

Esses acontecimentos apontam, como será explorado adiante, para a insuficiência da adoção isolada de mecanismos regulatórios estatais para a prevenção da disseminação de conteúdo fraudulento. 


\section{Literacia Digital como Alternativa}

O anseio por encontrar medidas que lidem com o problema sem prejudicar a liberdade de expressão tem incentivado pesquisadores e agentes públicos a buscarem medidas alternativas à simples regulação estatal, principalmente diante de exemplos recentes de como o combate a conteúdos fraudulentos pode deslizar para posturas autoritárias por parte daquele que detém o poder de decidir o que é falso ou não.

Essa foi a conclusão de um relatório intitulado "Fake news: public policy responses", no qual foram avaliadas criticamente as políticas públicas adotadas pela China e pela Itália com vistas a enfrentar as notícias falsas, bem como as respectivas consequências no campo dos direitos humanos. O relatório concluiu que a China é uma ilustração útil dos perigos presentes tanto no estabelecimento de estruturas de regulamentação preventivas (anteriores à publicação), quanto na definição muito ampla do que constitua uma notícia falsa ou um rumor, conceito que, para o governo chinês, inclui "minar a moralidade, o sistema socialista e a autenticidade da informação" (TAMBINI, 2017). Assim, a China "é um exemplo de país que elegeu como resposta pública a prática de limitar agressivamente a liberdade de expressão" e acabou por adotar uma "definição demasiado ampla do que constitui notícias falsas ou boatos/ rumores" (CARDOSO et al., 2018, p. 25).

Tais acontecimentos corroboram as palavras de Bobbio (1990, p. 214), quando afirma que é melhor "uma liberdade sempre em perigo, mas expansiva, do que uma liberdade protegida, mas incapaz de se desenvolver. Somente uma liberdade em perigo é capaz de se renovar. Uma liberdade incapaz de se renovar transforma-se, mais cedo ou mais tarde, numa nova escravidão". 
A Literacia Digital Frente ao Discurso Anticiência e às Fake News Doglas Cesar Lucas • Lucas Oliveira Vianna, et al...

É importante, pois, que se explorem alternativas que não apresentem o mesmo potencial danoso à liberdade de expressão, destacando-se, nesse sentido, a noção de "literacia digital" (digital literacy), diretamente ligada ao conceito de "cidadania digital"1.

Embora seja um construto extremamente amplo, para o qual são apresentadas definições consideravelmente divergentes por autores distintos, pode-se dizer, de modo geral, que a cidadania digital está relacionada com a capacidade de participação da pessoa no espaço online da sociedade, incluindo tanto a conectividade à Internet em si quanto às habilidades necessárias para a sua utilização (MOSSBERGER; TOLBERT; MCNEAL, 2007). O Conselho da Europa define-a como "a habilidade de se envolver de forma positiva, crítica e competente no ambiente digital" (MCDOUGALL et al., 2018, p. 12).

A literacia digital, por sua vez, transcende a mera capacidade de obter ou utilizar informações online de forma instrumental, englobando também, mais especificamente, a habilidade de formular questões sobre a fonte e o sentido da informação, sobre os interesses envolvidos na sua veiculação, em suma, compreender como a informação se relaciona com as forças sociais, políticas e econômicas (BUCKINGHAM, 2015, p. 15). Em essência, refere-se a um tipo de capacidade ética e social que complementa as habilidades técnicas e práticas necessárias ao uso das tecnologias digitais (MCDOUGALL et al., 2018, p. 12). Trata-se, em suma, da manifestação, no âmbito virtual, do mais amplo conceito de literacia midiática, que pode ser definida como "a habilidade de acessar a mídia, de entender e avaliar criticamente diferentes aspectos da mídia e dos contextos midiáticos para criar comunicações em uma variedade de contextos" (COMISSÃO EUROPEIA, 2007).

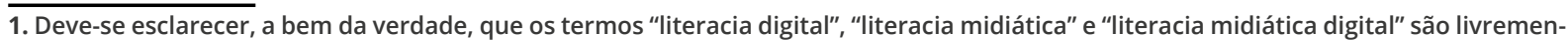
te utilizados, ao longo deste trabalho, como intercambiáveis entre si. 
Diversas pesquisas têm demonstrado que a educação em literacia midiática pode ter resultados positivos no conhecimento, habilidades e atitudes de estudantes em analisar e compreender de forma crítica a mídia (JEONG; CHO; HWANG, 2012; VRAGA; TULLY, 2016; WEBB; MARTIN, 2012). Mais do que isso, estudos têm demonstrado que esse tipo de educação é especialmente efetivo no que diz respeito a prevenir a crença em fake news, com pesquisas demonstrando que o nível de literacia midiática do indivíduo é inversamente proporcional a sua probabilidade de acreditar em e compartilhar notícias falsas (KAHNE; BOWYER, 2017).

A superioridade desta abordagem em relação à regulação estatal também está relacionada aos fenômenos cognitivos humanos denominados "viés de confirmação" e "viés de desconfirmação", os quais descrevem a tendência a, diante de evidências que desafiam nossas opiniões - e que, portanto, deveriam motivar-nos a reexaminar nossas visões -, reagir com um impulso psicológico de se agarrar ainda mais firmemente às nossas crenças equivocadas, em ambos os sentidos: buscar confirmação das nossas crenças prévias, em vez de informação que possa contradizer ou complicá-las (viés de confirmação); e ignorar ou rejeitar informações que desafiem as convicções pessoais (viés de desconfirmação), com a propensão, em se tratando de informação oriunda do espaço midiático, a desqualificar a mídia como desonesta e enviesada (MCDOUGALL et al., 2018), ou, no caso da regulação estatal, a classificar o Poder Público como autoritário e conspiracionista. Assim, paradoxalmente, o combate legislativo à desinformação pode, em alguns casos, intensificá-la.

A educação em literacia midiática, por sua vez, tem apresentado eficácia mesmo para mitigar os efeitos do viés de confirmação, com potencialidade, portanto, de tratar o fenômeno das fake news em sua 
raiz: a incapacidade de boa parte da população de aceitar uma informação que vá de encontro às suas convicções pessoais (MILLER, 2016). Por essa razão, a Comissão Europeia tem enfatizado reiteradamente a importância do desenvolvimento da literacia midiática digital como um instrumento de consecução da cidadania e prevenção às fake news, tanto por ser uma medida que não viola liberdades individuais, quanto por ser uma das poucas abordagens que apresenta efetividade a longo prazo (COMISSÃO EUROPEIA, 2018).

Em que pese as questões relativas à metodologia de tal instrução (faixa etária a ser aplicada, figura responsável pela ministração, nível escolar a ser inserida) serem objeto de considerável altercação (JEONG; CHO; HWANG, 2012; MCDOUGALL et al., 2018, p. 12), fato é que há consonância acerca dos benefícios positivos a longo prazo da instrução digital no combate à desinformação e prevenção da disseminação de notícias falsas.

Os benefícios de se optar pela literacia digital estão relacionados não apenas com a efetividade na prevenção da desinformação e com a manutenção da liberdade de expressão, mas também com o amadurecimento das responsabilidades e capacidades relacionadas à cidadania, com todos os efeitos a longo prazo que decorrem de uma sociedade amadurecida no ponto (CARDOSO et al., 2018, p. 26-27). A inclusão dessa natureza de ensino nos currículos escolares, particulares e públicos, tem o potencial de fomentar o amadurecimento do juízo crítico dos indivíduos, capacitando a comunidade externa a lidar com a celeuma da desinformação, concretizando, nesse ínterim, a sua cidadania digital.

\section{Conclusão}

“Não há fim para essa lista de peçonhas de ação instantânea, para as quais o único antídoto continua sendo a apura- 
ção meticulosa da verdade dos fatos, pois os 'reis' hodiernos, individuais ou coletivos, também estão under god" (MESQUITA, 2018 , p. 37). Contudo, deve-se ponderar que isso demanda muito tempo e capital, "elementos cada vez mais escassos no universo do jornalismo profissional" (MESQUITA, 2018, p. 37). Com efeito, o fenômeno da disseminação de notícias falsas como estratégia política têm, em muito, comprometido a qualidade do debate público, enviesado a compreensão da realidade social na esfera político-partidária e, prejudicando nesse ínterim também a compreensão pública sobre ciência, universidades e sua função social.

Conforme o exposto na primeira parte deste estudo, as fake news constituem a principal ferramenta de construção metanarrativa de discursos que tencionam alterar, sob a direção de propósitos políticos, a compreensão pública dos fatos na era da pós-verdade. A emergência desse fenômeno contribui para a constituição de um cenário em que o consenso científico deixa de ser valorizado como ferramenta de construção da verdade, ensejando o surgimento de discursos pseudocientíficos e anti-científicos.

Ao final, o presente estudo optou pela literacia digital como ferramenta adequada não só para a mitigação dos efeitos das fake news, como para a própria concretização da cidadania digital dos cidadãos. Tal abordagem tem mostrado particular eficácia como solução de longo prazo para o problema, uma vez que, em vez de impedir que a desinformação chegue ao indivíduo (objetivo cuja concretização plena é materialmente impossível), capacita e qualifica o sujeito para avaliar criticamente o conteúdo recebido.

\title{
Referências
}

\author{
ALBUQUERQUE, A. DE; QUINAN, R. CRISE EPISTEMOlóGICA E TEORIAS DA \\ conspiração: o discurso anti-CIÊnCIa do canal "Professor Terra Plana".
}


A Literacia Digital Frente ao Discurso Anticiência e às Fake News Doglas Cesar Lucas • Lucas Oliveira Vianna, et al...

Revista Mídia e Cotidiano, Rio de Janeiro, v. 13, N. 3, P. 83-104, Jan./ ABR.2020.

BarRagÁn, A. Cinco "fake news" que beneficiaram a Candidatura de Bolsonaro. Jornal Brasil El País. 19 out. 2018. Disponível em: https://Brasil. ELPAIS.COM/BRASIL/2018/10/18/ACTUALIDAD/1539847547_146583.HTML. ACESSO EM: 22 AGO. 2020.

BitTEnCOURT, M. C. A. A construção da figura política de Bolsonaro No El PAís: um EXERCícIO METOdOLÓGICO PARA ANÁlISE SOBRE PRODUÇÃo DE SENTIdo no jornalismo. Galáxia (São Paulo), N. 43, p. 168-187, 2020.

Bobbio, Norberto. A era dos Direitos. Trad. Carlos Nelson Coutinho. São Paulo: Ed. Campus, 1990.

BUCKINGHAM, D. Defining DIGITAL LITERACY-What do YOUNG PEOPLE NEED to know about digital media? Nordic Journal of Digital Literacy, Oslo, V. 10, P. 21-35, 2015.

CAPONI, S. COVID-19 No BRASIL: ENTRE O NEGACIONISMO E A RAZÃO NEOLIBERAL. Estudos Avançados, São Paulo, v. 34, N. 99, P. 209-224, 2020.

CARdoso, G; BALDI, V. (coord). As Fake News numa sociedade pós-verDAde: ConteXtualização, POTENCIAIS SOluçÕes e anÁlise. LisboA: OBerCom, 2018.

Cesarino, L. How Social Media Affords Populist Politics: remarks on liminality based on the brazilian case. Trabalhos em Linguística Aplicada, V. 59, N. 1, P. 404-427, 2020.

COMISSÃO EUROPEIA. A MULTI-DIMENSIONAL APPROACH TO DESINFORMATION. REPORT OF THE INDEPENDENT HIGH LEVEL GROUP ON FAKE NEWS AND ONLINE DIsinformation. Directorate-General for Communication Networks, Content ANd TeCHNOlogy. LuXEMBOURG, 2018. 
A Literacia Digital Frente ao Discurso Anticiência e às Fake News Doglas Cesar Lucas • Lucas Oliveira Vianna, et al...

COMISSÃO EUROPEIA. COMMUnication fROM the Commission to the European Parliament, the Council, the European Economic and Social Committee and the Committee of the Regions, A European approach to media LITERACY IN THE DIGITAL ENVIRONMENT, COM(2007) 833 FINAL.

CUNHA FILHO, M. Post-Truth and Authoritarianism: Reflections about the Antecedents and Consequences of Political Regimes Based on Alternative Facts. Brazilian Political Science Review, São Paulo, v. 13, N. 2, 2019.

FISHER, M.; TAUB, A. HOW EVERYDAY SOCIAL MEDIA USERS BECOME REAL-WORLD extremists. The New York Times, v. 25, 2018.

FRIAS filho, O. O que é falso sobre fake news. Revista USP, São Paulo, N. 116, P. 39-44, 2018.

GENESiNI, S. A pós-Verdade é uma notícia falsa. Revista USP, São Paulo, N. 116, P. 45-58, 2018.

19

GIACOIA JUNIOR, O. E SE O ERRO, A FABULAÇÃO, O ENGANO REVELAREM-SE TÃO essenciais quanto a verdade? Folha de S. Paulo, 19 fev. 2017.

hOBBS, R. Teach the Conspiracies. Knowledge Quest, v. 46, N. 1, P. 16-24, 2017.

JEONG, S.-H.; CHO, H.; HWANG, Y. Media Literacy Interventions: A Meta-Analytic Review. The Journal of Communication, v. 62, N. 3, P. 454-472, JUN. 2012.

KAHNE, J.; BOWYER, B. Educating for Democracy in a Partisan Age: Confronting the Challenges of Motivated Reasoning and Misinformation. American Educational Research Journal, v. 54, N. 1, P. 3-34, feV. 2017.

KAKUTANI, M. The death of truth. New York: Tim Duggan Books, 2018.

KAliL, I.; SANTINI, R. M. Coronavírus, Pandemia, Infodemia e Política. Relatório de pesquisa. Divulgado em 01 de abril de 2020. 21 p. São Paulo / RIO DE JANEIRO: FESPSP / UFRJ. 
A Literacia Digital Frente ao Discurso Anticiência e às Fake News Doglas Cesar Lucas • Lucas Oliveira Vianna, et al...

KEnRiCK, D. et Al. The science of antiscience thinking. Scientific AmeriCAN, v. 319, N. 1, P. 36-41, 2018.

LEMOS, V. A POLÊMICA SOBRE O TRATAMENTO PRECOCE PARA A COVID-19, CRITICAdo POR ENTIDADES MÉdicAs. BBC News Brasil. 7 Jul. 2020.

LEVITSKY, SteVen; ZIBLATT, Daniel. How democracies die. New York: BROADWAY BOOKS, 2018

MAZUI, G. Após cumprimentar apoiadores, Bolsonaro diz que é o resPONSÁVEL CASO TENHA SE CONTAMINADO. G1. 16 MAR. 2020.

MARQUES, J. Facebook apagou post de Bolsonaro por "alegaçÃo falsa" de cura para coronavírus. Folha de S. Paulo, 1 abr. 2020.

MARQUES SILVA, A. (NÃO) É SÓ UMA GRIPEZINHA: ARGUMENTAÇÃO E REALIDADE FORJADA NOS PRONUNCIAMENTOS DE JaIR Bolsonaro SOBRE A COVID-19. REVISTA Eletrônica de Estudos Integrados em Discurso e Argumentação, Ilhéus, N. 20, v. 2, P. 4-28, AGO. 2020.

MCDOUGALL, J. et al. Teaching media literacy in Europe: eVIDENCE of EFFECTIVE SCHOOL PRACTICES IN PRIMARY AND SECONDARY EDUCATION. LUXEMBOURG: Publications Office of the European Union, 2018.

MCinTYRe, L. Post-Truth. Cambridge: Mit Press, 2018.

MCinTyRe, L. The Scientific Attitude: Defending Science from Denial, Fraud, and Pseudoscience. Cambridge: Mit Press, 2019.

MESQUITA, F. L. A pós-VERDADE LEVARÁ À Pós-DEMOCRACIA?. Revista USP, SÃo PAULO, N. 116, P. 31-38, 2018.

Miller, A. C. Confronting Confirmation Bias: Giving Truth a Fighting Chance in the Information Age. Social Education, vol. 80, N. 5, P. 276 279, 2016. 
A Literacia Digital Frente ao Discurso Anticiência e às Fake News Doglas Cesar Lucas • Lucas Oliveira Vianna, et al...

MOSSBERGER, K.; TOlBeRT, C. J.; MCNEAL, R. S. Digital Citizenship: The Internet, Society, and Participation. Cambridge: Mit Press, 2007.

OLIVEIRA, T. DESINFORMAÇÃo CIENTÍFICA EM TEMPOS DE CRISE EPISTÊMICA: CIRCU-

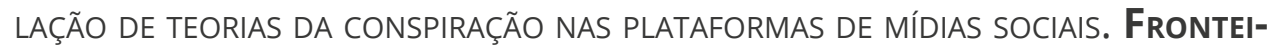
RAs - Estudos Midiáticos, v. 22, N. 1, JAN./ABR., 2020, P. 21-35.

OXFORD. Oxford Word of the Year 2016. Oxford Languages, 2016.

PARK, R. E. News as a Form of Knowledge: A Chapter in the Sociology of Knowledge. The American Journal of Sociology, v. 45, N. 5, p. 669-686, 1940.

RICARD, J., MEDEIROS, J. USING MISINFORMATION AS A POLITICAL WEAPON: COVID-19 and Bolsonaro in Brazil. The Harvard Kennedy School (HKS) Misinformation Review, v. 1, N. 2, 2020.

ROSENZWEIG, A. Understanding and Undermining Fake NeWs from the Classroom. Berkeley Review of Education, v. 7, N. 1, p. 105-112, 2017.

SUNSTEIN, C. R. ECHO CHAMBers: Bush v. GoRE, IMPEACHMENT, AND BEYOND. N.J.: Princeton University Press Princeton, NJ, 2001.

URIBE, G. Bolsonaro EStIMULA POPULAÇ̃̃o A INVADIR HOSPITAIS PARA FILMAR oferta de leitos. Folma de S. Paulo, 11 jun. 2020.

VAN DER Linden, S. et al. Inoculating the Public against Misinformation about Climate Change. Global challenges, Hoboken, v. 1, n. 2, 27 fev. 2017.

Viscardi, J. M. Fake News, Verdade e Mentira sob a Ótica de Jair Bolsonaro no Twitter. Trabalhos em Linguística Aplicada, Campinas, v. 59, n. 2, P. 1134-1157, AGO. 2020.

VOSOUGHI, S.; ROY, D.; ARAL, S. The SPREAD of TRUE AND FALSE NEWS ONLINE. SCIENCE, v. 359, N. 6380, P. 1146-1151, 9 MAR. 2018. 
A Literacia Digital Frente ao Discurso Anticiência e às Fake News Doglas Cesar Lucas • Lucas Oliveira Vianna, et al...

VRAGA, E. K.; TUlLy, M. Effectiveness of a Non-Classroom News Media Literacy Intervention Among Different Undergraduate Populations. Journalism \& Mass Communication Educator, v. 71, N. 4, P. 440-452, 2016.

WAKEFIELD, A. J. ET AL. ILEAL-LYMPHOID-NODULAR HYPERPLASIA, NON-SPECIFIC

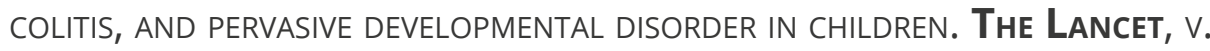
351, N. 9103, P. 637-641, FEV. 1998.

WeBB, T.; MARTin, K. Evaluation of a Us School-Based Media Literacy Violence Prevention Curriculum on Changes in Knowledge and Critical Thinking Among Adolescents. Journal of Children and Media, v. 6, N. 4, P. 430-449, Nov. 2012.

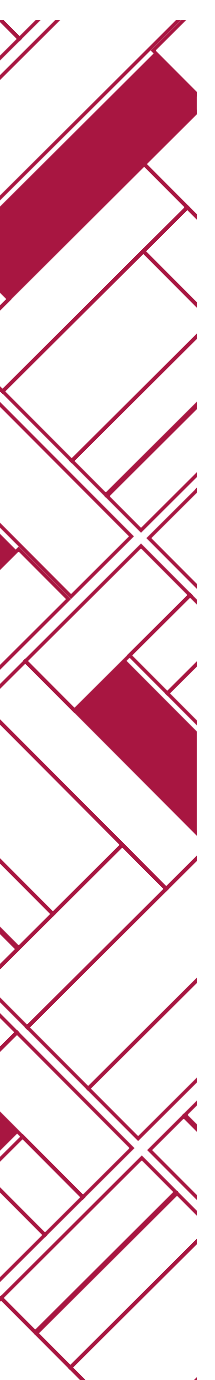

